\title{
Bence Jones Proteins Bind to a Common Peptide Segment of Tamm-Horsfall Glycoprotein to Promote Heterotypic Aggregation
}

\author{
Zhi-Qiang Huang, Katharine A. Kirk, Kevin G. Connelly, and Paul W. Sanders \\ Nephrology Research and Training Center, Division of Nephrology, Departments of Medicine, Physiology, and Biostatistics and \\ Biomathematics, University of Alabama at Birmingham, and Veterans Affairs Medical Center, Birmingham, Alabama 35292
}

\begin{abstract}
Bence Jones proteins (BJPs) are the major pathogenic factor causing cast nephropathy ("myeloma kidney") by coaggregation with Tamm-Horsfall glycoprotein (THP). Understanding the interaction between these proteins is therefore important in developing treatment strategies to prevent renal failure from cast formation in multiple myeloma. We developed an enzymelinked immunoassay to examine this phenomenon. Five different human BJPs (four $\kappa$ and one $\lambda$ immunoglobulin light chains) were used in this assay that demonstrated these proteins bound THP with different affinity. BJPs competed among themselves for binding to THP. The binding site was a peptide portion of THP since these proteins also bound deglycosylated THP. Also, one monoclonal antibody directed against a peptide segment of human THP prevented binding of THP to BJPs. By altering the conformation of THP, reducing agents decreased binding between these two proteins in concentration-dependent fashion. In turbidity studies, the monoclonal antibody that prevented binding and a reducing agent, dithiothreitol, decreased coaggregation. Deglycosylated THP did not coaggregate with BJPs. We concluded that ionic interaction between BJPs and a specific peptide binding site on THP promoted heterotypic coaggregation. The carbohydrate moiety of THP was also essential for coaggregation, perhaps by facilitating homotypic aggregation of THP. (J. Clin. Invest. 1993. 92:2975-2983.) Key words: renal failure • Bence Jones proteins - Tamm-Horsfell glycoprotein $\bullet$ reducing agents $\bullet$ multiple myeloma
\end{abstract}

\section{Introduction}

About half of patients presenting with multiple myeloma have concomitant renal insufficiency usually related to Bence Jones proteinuria (1-3). While a variety of renal lesions are associated with multiple myeloma (4), cast nephropathy, or "myeloma kidney," is perhaps best recognized and most common $(5,6)$. Using microdissection techniques, Oliver (7) demonstrated large numbers of casts obstructing tubule lumens of patients who died from myeloma and renal failure, hence the

Portions of this work have appeared in abstract form (1992. Clin. Res. 40:393a) and (1992. J. Am. Soc. Nephrol. 3:725a).

Address correspondence to Paul W. Sanders, M.D., Division of Nephrology/Department of Medicine, 642 Lyons-Harrison Research Building, University of Alabama at Birmingham, Birmingham, AL 35292-0007.

Received for publication 7 December 1992 and in revised form 16 July 1993.

The Journal of Clinical Investigation, Inc.

Volume 92, December 1993, 2975-2983 term cast nephropathy. These intraluminal casts are composed of Bence Jones protein (BJP) ${ }^{1}$ and Tamm-Horsfall glycoprotein (THP) (8), a protein that is synthesized by cells of the thick ascending limb of the loop of Henle $(9,10)$ and is the major constituent of urinary casts (11). As shown originally by Koss et al. (12) and confirmed by others (13-19), cast nephropathy can be reproduced in mice and rats by parenteral injection of purified human Bence Jones protein. We have demonstrated that cast-forming human Bence Jones proteins coaggregate with Tamm-Horsfall glycoprotein to obstruct the distal nephron (14-16). In addition, intravenous infusion of nephrotoxic human Bence Jones protein in rats elevates proximal tubule pressure and simultaneously decreases single nephron glomerular filtration rate; intraluminal protein casts were identified in these kidneys (18). Thus, intraluminal obstruction from cast formation appears to be a prominent cause of acute renal failure in multiple myeloma. Because of the central role of Bence Jones proteins and Tamm-Horsfall glycoprotein in renal failure from cast nephropathy, our current study examines in detail the binding interaction between these proteins. Characterization of this interaction allows development of new therapies that focus specifically on this basic pathogenic mechanism of cast nephropathy and may serve to decrease morbidity and mortality from renal failure in multiple myeloma.

\section{Methods}

Protein preparation. Five different BJPs were used in these studies. $\mathrm{BJP}_{\text {mic }}, \mathrm{BJP}_{\text {rap }}$, and $\mathrm{BJP}_{\text {don }}$ were purified from the urine of patients who had multiple myeloma and renal failure using techniques described previously $(20)$. These proteins corresponded to those proteins (previously referred to as BJP1, BJP2, and BJP3, respectively) used in previous studies $(14,15)$. Because of the relative abundance of these proteins and the requirement of large amounts of protein in some experiments, these three BJPs were used in the majority of studies. $\mathrm{BJP}_{\text {len }}$ was from a patient who had no clinical evidence of renal dysfunction, although under conditions of mild depletion of extracellular fluid volume, this protein obstructed the rat distal nephron (16). BJP ${ }_{r h y}$ was from a patient who had renal failure and histopathologic evidence of cast nephropathy. These two proteins were generous gifts from Dr. Alan Solomon (University of Tennessee Medical Center, Knoxville, TN). All BJPs except BJP don were kappa light chains. THP was purified from the urine of a normal male volunteer in standard fashion (15) by precipitation with $\mathrm{NaCl}, 0.64 \mathrm{M}$, followed by centrifugation at $48,000 \mathrm{~g}$ for $15 \mathrm{~min}$. The pellet was resuspended with deionized water, then dialyzed against deionized water for $72 \mathrm{~h}$. The protein was lyophilized and stored at $-20^{\circ} \mathrm{C}$. Electrophoresis of this product using a $7.5 \%$ polyacrylamide gel (SDS-PAGE) demonstrated a single band at $\sim 100 \mathrm{kD}$.

1. Abbreviations used in this paper: BJP, Bence Jones protein; THP, Tamm-Horsfall glycoprotein. 
Western blotting using rabbit polyclonal antiserum against human THP (Biomedical Technologies Inc., Stoughton, MA) confirmed the identity of this band as THP.

Several experiments used deglycosylated THP, which was prepared by dissolving THP, $10 \mathrm{mg} / \mathrm{ml}$, in $1 \%$ SDS (Bio-Rad Laboratories, Richmond, CA), boiling for $5 \mathrm{~min}$, then mixing in sodium phosphate buffer, pH 8.6, containing $160 \mathrm{mM}$ sodium phosphate, $5 \mathrm{mM} \mathrm{1,10-}$ phenanthroline, $0.3 \%$ Triton X-100, and $100 \mathrm{U} / \mathrm{ml} N$-glycosidase F (PNGase F; Boehringer Mannheim Biochemical, Indianapolis, IN). The final concentration of THP was $0.5 \mathrm{mg} / \mathrm{ml}$. The mixture was incubated at $37^{\circ} \mathrm{C}$ for $18 \mathrm{~h}$. After the incubation, the buffer was changed to $1 \%$ Tween 20 in PBS with at least three buffer exchanges using a microconcentrator (Centricon 30; Amicon, W. R. Grace \& Co., Beverly, MA). Deglycosylated THP was then aliquoted and stored at $-20^{\circ} \mathrm{C}$. Successful deglycosylation of THP was confirmed using a glycan detection kit (Boehringer Mannheim Biochemical), which detects the presence of carbohydrate with as little as $10 \mathrm{ng}$ of glycoprotein.

A mouse monoclonal antibody against purified human THP was raised in our laboratory and purified from the medium using ammonium sulfate precipitation and a protein G column (Pharmacia LKB Biotechnology Inc., Piscataway, NJ). To determine whether this monoclonal antibody reacted with the peptide portion of THP, THP and deglycosylated THP underwent electrophoresis (SDS-PAGE) using a $12 \%$ polyacrylamide gel. After transfer of these proteins onto nitrocellulose and washing in standard fashion, the membrane was incubated with our mouse anti-human THP monoclonal antibody, followed by rabbit anti-mouse IgG antibody conjugated with horseradish peroxidase (Bio-Rad, Melville, NY). After additional washes, the membrane was developed using peroxidase substrate $(0.1 \mathrm{mM}$ Tris/ $\mathrm{HCl}, \mathrm{pH} 7.4$, $0.8 \mathrm{mg} / \mathrm{ml} \mathrm{3,3'-diaminobenzidine,} 0.01 \%$ hydrogen peroxide).

Binding analysis studies. To characterize the binding of THP with BJPs, an enzyme-linked immunoassay was developed. In these and subsequent studies that compared binding of the various BJPs to human THP, all five proteins were examined simultaneously on the same microplate. Wells of microplates were coated with BJPs, $2 \mu \mathrm{g} / \mathrm{ml}$ in PBS, pH 7.4, and incubated overnight at room temperature. The wells were washed three times with $0.05 \%$ Tween 20 in PBS. The remaining unoccupied binding sites in the wells were blocked by incubating with $1 \%$ BSA in PBS for $1 \mathrm{~h}$ at room temperature. Native THP or deglycosylated THP, suspended in $1 \%$ Tween 20 in PBS, was added to the wells ( $100 \mu \mathrm{l} /$ well) after additional washes with $0.05 \%$ Tween 20 in PBS. The microplates were incubated for $30 \mathrm{~min}$ at room temperature. Polyclonal rabbit antibody against human THP, 1:3,000 dilution in PBS, was added to the wells, followed by horseradish peroxidase-conjugated goat anti-rabbit IgG antibody (Bio-Rad, Melville, New York), 1:1,000 dilution in PBS. Microplates were incubated with each of the antibodies for $1.5 \mathrm{~h}$ at room temperature followed at the end of each incubation by three washes with $0.05 \%$ Tween 20 in PBS. Wells were developed using azino-bis (3-ethylbenzthiazoline-6-sulfonic acid) (Sigma Chemical Co., St. Louis, MO), $2.5 \mathrm{mg} / \mathrm{ml}$, in citrate-phosphate buffer, $\mathrm{pH}$ 4.2. Optical density was determined at $405 \mathrm{~nm}$ using a microplate reader (THERMO max $_{\text {max }}$ Molecular Devices Corp., Menlo Park, CA). Binding curves were constructed for each of the five BJPs by varying the amount of THP in the incubating solution between 1 and 1,000 $\mu \mathrm{g} / \mathrm{ml}$. In other experiments, to examine the effect of duration of exposure on binding of THP to BJPs, THP, $150 \mu \mathrm{g} / \mathrm{ml}$, was incubated with each of the five BJPs for 0-60 min. THP bound to BJPs in the wells was determined as described above.

In other studies, all five BJPs were biotinylated in standard fashion (21), using sulfo- $N$-hydroxysuccinimide biotin (ImmunoPure SulfoNHS-Biotin; Pierce Chemical Co., Rockford, IL), followed by dialysis against PBS at $4^{\circ} \mathrm{C}$ for $24 \mathrm{~h}$ to remove free biotin. The relative amount of biotinylation per $\mathrm{mg}$ BJP was determined as follows. All five biotinylated proteins, $100 \mu \mathrm{g} / \mathrm{ml}$, were blotted simultaneously onto nitrocellulose membrane, which was then incubated $30 \mathrm{~min}$ in PBS containing $1 \%$ BSA. After washing three times with $0.05 \%$ Tween 20 in PBS, the membrane was incubated in PBS that contained 1\% BSA and streptavi- din-conjugated horseradish peroxidase (Southern Biotechnology Associates, Inc., Birmingham, AL), 1:1,000 dilution. The membrane was developed using peroxidase substrate $(0.1 \mathrm{mM}$ Tris $/ \mathrm{HCl}, \mathrm{pH} 7.4,0.8$ $\mathrm{mg} / \mathrm{ml} 3,3^{\prime}$-diaminobenzidine, $0.01 \%$ hydrogen peroxide). The color reactions of each dot blot were quantitated using a densitometer (model 620 video densitometer; Bio-Rad Laboratories, Richmond, $\mathrm{CA}$ ) and were used to determine the relative ratios of biotinylation among the five proteins. These correction factors for biotinylation were used in subsequent studies that used these biotinylated proteins. To quantitate binding of each of the BJPs to wells of microplates, initially 1 part biotinylated BJP was mixed with 14 parts unbiotinylated BJP in PBS to produce a final protein concentration of $2 \mu \mathrm{g} / \mathrm{ml}$. Wells of microplates were then incubated with each BJP solution overnight at room temperature. After blocking with $1 \%$ BSA in PBS and washing with $0.05 \%$ Tween 20 in PBS, streptavidin-conjugated horseradish peroxidase, 1:3,000 dilution in PBS, was added to the wells, followed by peroxidase substrate. Optical density was determined at $405 \mathrm{~nm}$ using a microplate reader (THERMO max $_{\max }$, Molecular Devices Corporation). In a separate experiment, wells of microplates were coated using THP, 2 $\mu \mathrm{g} / \mathrm{ml}$, overnight at room temperature. After blocking and washing, each biotinylated BJP, $0-300 \mu \mathrm{g} / \mathrm{ml}$, was added to the wells, which were incubated for $30 \mathrm{~min}$ at room temperature. After extensive washes, streptavidin-conjugated horseradish peroxidase, 1:3,000 dilution in PBS, was added to the wells, followed by peroxidase substrate. Optical density was determined at $405 \mathrm{~nm}$ using a microplate reader.

Effects of reducing agents. To define further the binding interaction between BJP and THP, we included reducing agents in our binding assay. After coating wells of microplates with a test BJP and washing and blocking as described above, $50 \mu 1 \beta$-mercaptoethanol, $250 \mathrm{mM}$, was added to the wells, followed by $50 \mu \mathrm{l} \mathrm{THP,} 300 \mu \mathrm{g} / \mathrm{ml}$. The plate was shaken once and incubated for $30 \mathrm{~min}$ at room temperature. Other reducing agents, including cysteamine, penicillamine, dithiothreitol, $\mathrm{L}$-cysteine, and $\mathrm{N}$-acetyl-L-cysteine were also tested in this fashion in doses between 0 and $300 \mathrm{mM}$ using $\mathrm{BJP}_{\text {mic }}, \mathrm{BJP}_{\text {rap }}$, and $\mathrm{BJP}_{\text {don }}$. Two closely related compounds, cystamine and cysteamine- $S$-phosphate, 0-300 mM, were used as controls because they did not possess free sulfhydryl groups and therefore did not serve as reducing agents. In a separate experiment, after incubating wells that contained the five BJPs with THP for $30 \mathrm{~min}$ at room temperature, $\beta$-mercaptoethanol, 250 $\mathrm{mM}$, was added after washing, and wells were incubated another 10 min. After extensive washing, THP bound on the wells was detected as described above. The amount of reducing agent required to inhibit binding of THP by $50 \%\left(E_{50}\right)$ was calculated from these data.

To observe whether BJP and THP possessed free sulfhydryl groups through which binding may have occurred, $20 \mu \mathrm{l}$ of $\mathrm{BJP}_{\text {mic }}, \mathrm{BJP}_{\text {rap }}$, $\mathrm{BJP}_{\text {don }}$, and THP, $1 \mathrm{mM}$ in PBS, pH 7.4, were mixed with $100 \mu \mathrm{l}$ 5,5'-dithiobis (2-nitrobenzoic acid) (Ellman's reagent; Cayman Chemical Co., Inc., Ann Arbor, MI) in a microplate and incubated for $30 \mathrm{~min}$ at room temperature. $N$-Acetyl-L-cysteine was used as a positive control. Optical density was read at $405 \mathrm{nM}$ using a microplate reader. In a separate experiment, $\mathrm{BJP}_{\text {mic }}, 1 \mathrm{mg} / \mathrm{ml}$, was incubated with $1 \mathrm{mM}$ and $10 \mathrm{mM}$ iodoacetamide, a potent thiol-blocking agent. These treated $\mathrm{BJP}_{\text {mic }}$ preparations were diluted to $2 \mu \mathrm{g} / \mathrm{ml}$ and used to coat the wells of microplates. Binding assay was performed as described above and compared to binding reaction between THP and untreated BJP mic $_{\text {. }}$

To examine whether reducing agents affected directly either BJP or THP, wells of microplates were coated with $\mathrm{BJP}_{\text {mic }}, \mathrm{BJP}_{\text {rap }}, \mathrm{BJP}_{\text {don }}$, and THP, $2 \mu \mathrm{g} / \mathrm{ml}$, and were washed and blocked as described. Dithiothreitol, 0-100 $\mathrm{mM}$, was added to the wells and incubated for $30 \mathrm{~min}$ at room temperature. After extensive washing with $0.05 \%$ Tween 20 in PBS, THP, $150 \mu \mathrm{g} / \mathrm{ml}$, was added to the wells coated with BJPs, followed by rabbit anti-human THP and goat anti-rabbit IgG antibody conjugated with horseradish peroxidase. $\mathrm{BJP}_{\text {mic }}, \mathrm{BJP}_{\text {rap }}$, and $\mathrm{BJP}_{\text {don }}, 1$ $\mathrm{mg} / \mathrm{ml}$, were added to the wells coated with THP followed by goat anti-kappa or anti-lambda light chain antibodies (Organon Teknika, West Chester, PA) and rabbit anti-goat IgG antibody conjugated with horseradish peroxidase (Bio-Rad, Melville, NY). The plates were 
washed again and developed using the same substrate. Optical density was read at $405 \mathrm{~nm}$.

Competition studies. To determine whether different BJPs bound to the same site on THP, wells of microplates were coated with the five BJPs, $2 \mu \mathrm{g} / \mathrm{ml}$ in PBS, and incubated overnight at room temperature. After washing with $0.05 \%$ Tween 20 in PBS and blocking with $1 \%$ BSA in PBS for $30 \mathrm{~min}, 50 \mu \mathrm{l}$ of $\mathrm{BSA}$ or $\mathrm{BJP}_{\text {mic }}, \mathrm{BJP}_{\text {rap }}$, and $\mathrm{BJP}_{\text {don }}, 0.02-60$ $\mathrm{mg} / \mathrm{ml}$, was added to the wells, followed by $50 \mu \mathrm{l} \mathrm{THP,} 300 \mu \mathrm{g} / \mathrm{ml}$. The plates were shaken to mix THP and BJPs thoroughly and incubated for $30 \mathrm{~min}$ at room temperature. After extensive washing, THP bound to wells was determined as described above.

In other experiments, our mouse monoclonal anti-human THP antibody, $0.1-33 \mu \mathrm{g} / \mathrm{ml}$, was used as a competitor in this binding assay. Another commercial mouse monoclonal anti-human THP antibody was purified from mouse ascitic fluid (Accurate Chem. \& Sci. Corp., Westbury, NY) using $50 \%$ ammonium sulfate precipitation and a THP-conjugated Sepharose 4B (Sigma Chemical Co.) affinity column. Final antibody concentration was adjusted to $33 \mu \mathrm{g} / \mathrm{ml}$ before use. BSA served as a control in these experiments.

Finally, because human THP contains an RGD (arginine-glycineaspartic acid) peptide sequence $(10,22)$ which is a common binding site for adhesion molecules (23), we used a synthesized RGD peptide (Bachem California, Torrance, CA ), $0.0075-2.5 \mathrm{mg} / \mathrm{ml}$, as a competitor in these studies.

Turbidity measurements. As described previously $(15,16)$, to observe coaggregation of THP with BJPs in vitro, turbidity of solutions containing THP and deglycosylated THP, $0.125 \mu \mathrm{g} / \mathrm{ml}$ in PBS, $\mathrm{pH} 7.4$, was determined using a spectrofluorometer (M-series; Photon Technology International, Inc., South Brunswick, NJ) at an excitation and monitoring wavelength of $488 \mathrm{~nm}$. After confirming a stable baseline, change in turbidity was determined after adding $\mathrm{BJP}_{\text {mic }}, \mathrm{BJP}_{\text {rap }}$, and $\mathrm{BJP}_{\text {don }}, 0.06 \mathrm{mg} / \mathrm{ml}$. These concentrations of proteins were used because they reflected the relative amounts and ratios of these proteins found in the distal nephron. Furthermore, they were identical to those used previously (16). These protein ratios differed from those used in the initial binding analysis studies but were similar to those experiments that used biotinylated BJPs. In other studies, THP was preincubated with our monoclonal anti-human THP antibody, $3.5 \mu \mathrm{g} / \mathrm{ml}$, and change in turbidity after addition of BJP was monitored. To ob-

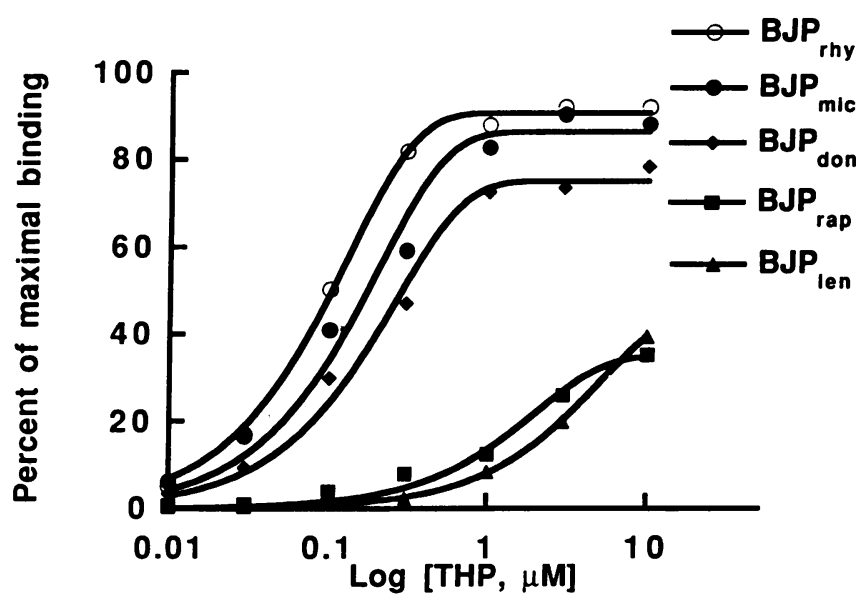

Figure 1. Effect of increasing concentrations of THP on binding to BJPs ( $n=5$ experiments). In these experiments, the wells had been coated with the test BJP, $2 \mu \mathrm{g} / \mathrm{ml}$, and THP, $0-1,000 \mu \mathrm{g} / \mathrm{ml}$, was added subsequently. Data from each experiment were standardized by making the maximum optical density for each experiment equal to $100 \%$. As indicated by the initial slopes of the curves, the affinities of BJPs to THP varied. BJP ${ }_{m i c}$ and BJP $_{r h y}$ had the highest affinities to THP, while $\mathrm{BJP}_{\text {rap }}$ and $\mathrm{BJP}_{\text {len }}$ had the lowest (Table I).

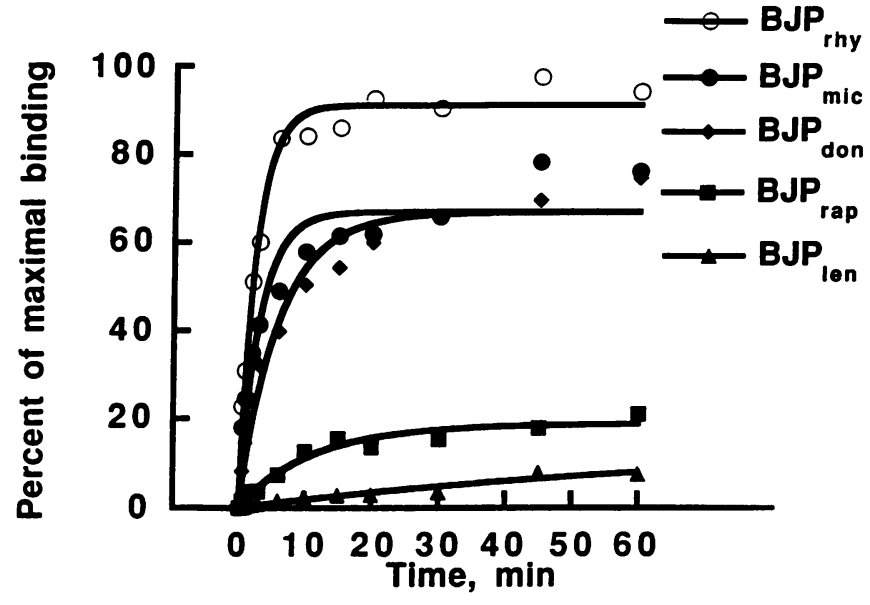

Figure 2. Time course of THP binding to BJPs ( $n=5$ experiments). A constant amount of THP, $150 \mu \mathrm{g} / \mathrm{ml}$, was added to wells coated with BJP, $2 \mu \mathrm{g} / \mathrm{ml}$. Data from each experiment were standardized by making the maximum optical density for each experiment equal to $100 \%$. Initial binding rates of these proteins to THP differed and are shown in Table I. Again, BJP ${ }_{m i c}$ and BJP ${ }_{r h y}$ had the highest initial slopes, $\mathrm{BJP}_{\text {rap }}$ and $\mathrm{BJP}_{\text {len }}$ had the lowest.

serve the effect of reducing agents on the coaggregation, changes in turbidity of THP-containing solutions were monitored after addition of dithiothreitol, $1.5 \mathrm{mM}$.

Statistical analysis. Two statistical models were used to estimate parameters of interest in the binding analysis studies. The first was a two-parameter, cumulative negative exponential with the parameters being a maximum response and either an initial slope or the $\mathrm{EC}_{50}$, as desired. The second was a logistic model in which the logarithm of the concentration was the independent variable. This second model can be rearranged to handle both increasing and decreasing responses. The parameters for the logistic were a maximum response, the $\log \left(\mathrm{EC}_{50}\right)$ or the $\mathrm{EC}_{50}$, and the slope at $\log \left(\mathrm{EC}_{50}\right)$. In a few cases, a nonzero minimum response was also required. Estimation was performed using the multivariate secant algorithm (DUD), a derivative-free method available in the nonlinear least squares procedure (NLIN) of the Statistical Analysis System (SAS Institute, Inc., Cary, NC). This method produces estimated standard errors for the parameter estimates and $95 \%$ confidence interval estimates of the parameters. The two-parameter model appeared to be adequate to describe the association curves; dose response and competition curves more often required the logistic.

\section{Results}

Binding analyses. All five BJPs bound THP; these interactions displayed saturation kinetics (Figs. 1 and 2). These BJPs presented varying binding affinities and initial binding rates to THP (Table I). BJP ${ }_{\text {mic }}$ and BJP rhy bound THP most avidly, while $\mathrm{BJP}_{\text {rap }}$ and $\mathrm{BJP}_{\text {len }}$ had the lowest affinities (Figs. 1 and 2). Using biotinylated BJPs, binding of the BJPs to wells of microplates did not differ (Fig. 3). Therefore, efficiency of coating wells of microplates was not a variable in these and subsequent studies that used microplates coated initially with BJP. Experiments that examined binding of biotinylated BJPs to THPcoated wells also showed results comparable to the initial binding studies, with $\mathrm{BJP}_{r h y}, \mathrm{BJP}_{m i c}$, and $\mathrm{BJP}_{d o n}$ demonstrating high binding affinities for THP, and $\mathrm{BJP}_{\text {rap }}$ and $\mathrm{BJP}_{\text {len }}$ low affinities 
Table I. Half-maximal Binding Concentration $\left(E C_{50}\right)$ and Initial Binding Rates of THP with Each of the Five BJPs

\begin{tabular}{lrccrr}
\hline \multicolumn{1}{c}{ Protein } & BJP $_{\text {rhy }}$ & BJP $_{\text {mic }}$ & BJP $_{\text {don }}$ & BJP $_{\text {rap }}$ & BJP $_{\text {len }}$ \\
\hline $\mathrm{EC}_{50}, \mu \mathrm{M}$ & $8.9 \pm 0.5$ & $13.8 \pm 2.3$ & $17.9 \pm 2.2$ & $144.5 \pm 24.9$ & $363.0 \pm 19.1$ \\
Initial binding rate, \% bound per min & $36.3 \pm 2.5$ & $21.6 \pm 3.1$ & $11.1 \pm 1.2$ & $1.7 \pm 0.2$ & $0.2 \pm 0.0$ \\
\hline
\end{tabular}

(data not shown). Deglycosylated THP also bound to all five BJPs in a fashion similar to native THP (Fig. 4).

Reducing agents inhibited binding of THP to BJPs in a dose-dependent fashion. Dithiothreitol was the most potent inhibitor (Table II). Cystamine and cysteamine- $S$-phosphate, two compounds that did not contain free sulfhydryl groups, had no effect on the binding of THP to BJPs. Similarly, $\beta$-mercaptoethanol decreased binding of THP to BJPs (Fig. 5). After THP bound to BJPs, incubating with this reducing agent also removed bound THP (Fig. 5). Using Ellman's reagent, free sulfhydryl groups on $\mathrm{BJP}_{\text {mic }}, \mathrm{BJP}_{\text {rap }}, \mathrm{BJP}_{d o n}$, and THP were not detected. When $\mathrm{BJP}_{\text {mic }}$, $\mathrm{BJP}_{\text {rap }}$, and $\mathrm{BJP}_{\text {don }}$ coated on the wells of microplates were pretreated with dithiothreitol, which was removed before addition of THP, binding of THP was not influenced. In contrast, when THP coated on the wells of microplates was pretreated with dithiothreitol before addition of $\mathrm{BJPs}$, binding of $\mathrm{BJP}_{\text {mic }}, \mathrm{BJP}_{\text {rap }}$, and $\mathrm{BJP}_{\text {don }}$ decreased with increasing doses of dithiothreitol. In these studies, the amount of dithiothreitol required to inhibit the binding of THP by $50 \%$ $\left(\mathrm{ED}_{50}\right)$ was $0.07 \mathrm{mM}$ for $\mathrm{BJP}_{\text {mic }}, 0.7 \mathrm{mM}$ for $\mathrm{BJP}_{\text {rap }}$, and 0.7 $\mathrm{mM}$ for $\mathrm{BJP}_{\text {don }}$.

Competition studies. $\mathrm{BJP}_{\text {mic }}, \mathrm{BJP}_{\text {rap }}$, and $\mathrm{BJP}_{\text {don }}$ competed with all five BJPs for binding to THP coated on wells of microplates (Fig. 6). Competition occurred in a dose-dependent fashion. Among the different proteins, competition depended upon

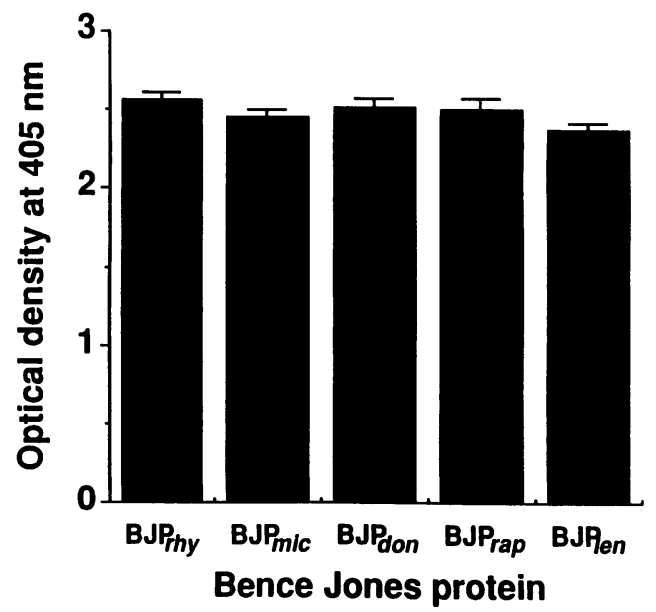

Figure 3. To determine whether binding of the five BJPs to microplate wells differed, solutions containing biotinylated and unbiotinylated BJPs, in a final concentration of $2 \mu \mathrm{g} / \mathrm{ml}$ in PBS, were used to coat wells ( $n=12$ for each BJP), which were incubated overnight. After washing and blocking, the wells were developed using streptavidinconjugated horseradish peroxidase and peroxidase substrate. Optical density, which was corrected for degree of biotinylation of each protein (see Methods), did not differ $(P=0.1277)$ among the five proteins. the binding affinities of the individual BJP. $\mathrm{BJP}_{m i c}$ and $\mathrm{BJP}_{d o n}$ had higher affinities for THP and served as stronger competitors than $\mathrm{BJP}_{\text {rap }}$, which had a low affinity for THP. BSA did not inhibit binding of THP to BJPs. When a mouse monoclonal antibody directed against human THP was used as a competitor, binding between BJPs and THP was inhibited in a dose-dependent manner (Fig. 7). This monoclonal antibody reacted with an epitope on the peptide portion of human THP (Fig. 8). BSA, a commercial monoclonal anti-THP antibody, and the RGD peptide did not decrease binding of THP to BJPs.

Turbidity measurements. $\mathrm{BJP}_{\text {mic }}, \mathrm{BJP}_{\text {rap }}$, and $\mathrm{BJP}_{\text {don }}$ increased turbidity of solutions containing THP. Hairlike particles in these solutions were seen with the naked eye at the end of these tests. In contrast, turbidity did not increase when the BJPs were added to solutions containing deglycosylated THP (Fig. 9). When our monoclonal anti-human THP antibody was preincubated with THP, the increase in turbidity that occurred with $\mathrm{BJP}_{\text {mic }}, \mathrm{BJP}_{\text {rap }}$, and $\mathrm{BJP}_{\text {don }}$ was lessened by $40 \%$ (Fig. 10) ( $n=4$ experiments for each protein). The simultaneous addition of dithiothreitol with BJP to THP-containing solutions reduced the incremental increase in turbidity by $40 \%$ (Fig. 11) ( $n=4$ experiments). Pretreatment of THP with dithiothreitol, $1.5 \mathrm{mM}$, further reduced subsequent coaggregation with BJP by $\sim 80 \%$.

\section{Discussion}

By coaggregating with THP in the lumen of the distal nephron, BJPs are the principle pathogenic factor in cast nephropathy, or myeloma kidney $(15,16)$. The current studies were de-

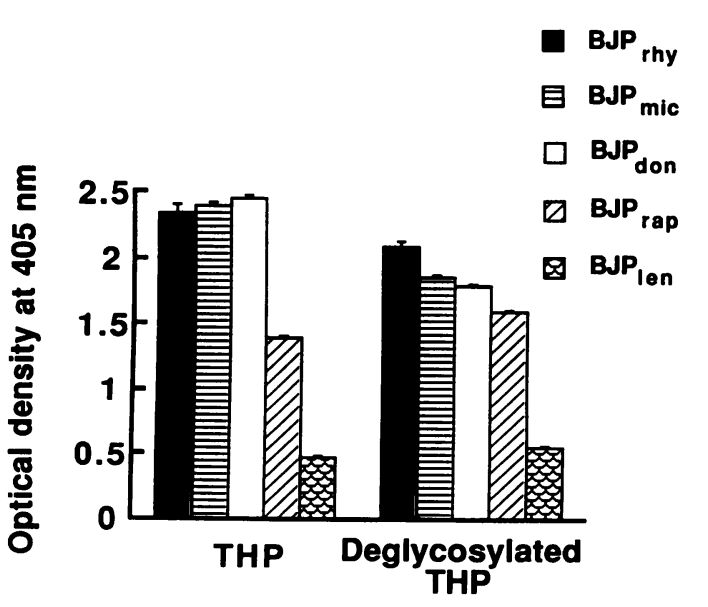

Figure 4. Binding of either THP or deglycosylated THP, $150 \mu \mathrm{g} / \mathrm{ml}$, to microwells coated with BJP, $2 \mu \mathrm{g} / \mathrm{ml}$. Binding affinities between THP and deglycosylated THP did not differ $(n=3$ experiments for each group). 
Table II. Effect of Reducing Agents on Prevention of Binding of THP to BJPS

\begin{tabular}{|c|c|c|c|c|}
\hline \multirow[b]{2}{*}{ Reducing agent } & \multirow[b]{2}{*}{ Chemical formula } & \multicolumn{3}{|c|}{$\mathrm{ED}_{\mathbf{s 0}}, \mathrm{mM}$} \\
\hline & & $\mathrm{BJP}_{\text {mic }}$ & $\mathbf{B J P}_{\text {rap }}$ & $\mathbf{B J P}_{d o n}$ \\
\hline Cysteamine & $\begin{array}{c}\mathrm{HS}-\mathrm{CH}_{2}-\mathrm{CH}_{2}-\mathrm{NH}_{2} \\
\mathrm{H}_{3} \mathrm{C} \quad \mathrm{NH}_{2}\end{array}$ & $22.7 \pm 1.8$ & $32.5 \pm 53.1$ & $2.8 \pm 0.6$ \\
\hline Penicillamine & $\begin{array}{c}\mathrm{HS}-\mathrm{C}-\mathrm{CH}-\mathrm{COOH} \\
\mathrm{CH}_{3} \\
\mathrm{HO} \mathrm{OH}\end{array}$ & $54.2 \pm 16.1$ & $0.2 \pm 0.1$ & $2.8 \pm 0.9$ \\
\hline Dithiothreitol & $\mathrm{HS}-\mathrm{CH}_{2} \mathrm{CHCHCH}_{2}-\mathrm{SH}$ & $2.4 \pm 0.1$ & $4.3 \pm 3.6$ & $0.7 \pm 2.4$ \\
\hline Cysteine & $\begin{array}{r}\mathrm{HS}-\mathrm{CH}_{2} \mathrm{CHCOOH} \\
\mathrm{NHCOCH}\end{array}$ & $17.8 \pm 1.1$ & $26.3 \pm 7.2$ & $7.7 \pm 2.4$ \\
\hline$N$-acetyl-cysteine & $\mathrm{HS}-\mathrm{CH}_{2} \mathrm{CHCOOH}$ & $57.9 \pm 5.3$ & $8.9 \pm 1.3$ & $36.0 \pm 12.4$ \\
\hline Cystamine & $\begin{array}{l}\mathrm{S}-\mathrm{CH}_{2} \mathrm{CH}_{2} \mathrm{NH}_{2} \\
\text { S- } \mathrm{CH}_{2} \mathrm{CH}_{2} \mathrm{NH}_{2}\end{array}$ & No effect & No effect & No effect \\
\hline Cysteamine- $S$-phosphate & $\mathrm{PO}_{4}-\mathrm{S}-\mathrm{CH}_{2} \mathrm{CH}_{2} \mathrm{NH}_{2}$ & No effect & No effect & No effect \\
\hline
\end{tabular}

signed to examine the binding interaction between these proteins. Using an enzyme-linked immunoassay, we found that BJPs bound human THP with different affinities. BJPs com-peted among each other for binding to THP. A monoclonal antibody directed against a peptide portion of THP served as a competitive inhibitor of binding (Fig. 7). BJPs also bound THP that had been completely deglycosylated enzymatically. These data demonstrated that BJPs bound to a common peptide segment on THP. Reducing agents interacted with THP to prevent subsequent binding to BJPs. In agreement with others (24), Ellman's reagent did not detect free thiol groups on THP, suggesting that the binding interaction between these proteins was not covalent. In turbidity studies, both the monoclonal antibody, which prevented binding of BJP to THP, and the reducing agent, dithiothreitol, decreased heterotypic aggregation. Although deglycosylated THP bound to BJPs, coaggregation with BJPs did not occur. In summary, these combined data demonstrated that BJPs bound through ionic interaction to a common peptide region on THP. This heterotypic aggregation was dependent on this interaction as well as the carbohydrate moiety of THP.

THP is composed of 616 amino acids and has eight potential asparagine-linked glycosylation sites $(9,10,22)$. Intramolecular disulfide bonds formed between 48 cysteine residues interspersed throughout the molecule are important in keeping a rigid structure; reducing agents do not dissociate the molecule into smaller subunits $(9,22,24)$. The major secondary structure is a $\beta$-sheet with a regular zig-zag appearance $(9,25)$. The carbohydrate component accounts for $30 \%$ of the total molecular weight and is responsible for homotypic aggregation which promotes gel formation $(9,25)$. In the present study, the carbohydrate moiety of THP did not influence the binding efficiency to BJPs, which also bound to deglycosylated THP. Thus, unlike other proteins, such as interleukin-1, which binds to the carbohydrate moiety of THP $(10,26)$, our data demonstrated that BJP was not a lectinlike protein. Previous work found that colchicine, which decreased carbohydrate content of THP (mainly sialic acid), prevented coaggregation of THP with BJP (16). In our present study, complete deglycosylation of THP also abolished coaggregation. Thus, the carbohydrate moiety was essential in heterotypic aggregation of THP and BJP by allowing simultaneously homotypic aggregation among the molecules of THP $(9,25)$. Possibly, the binding of BJP to THP also changed the net electric charge on the surface of THP to

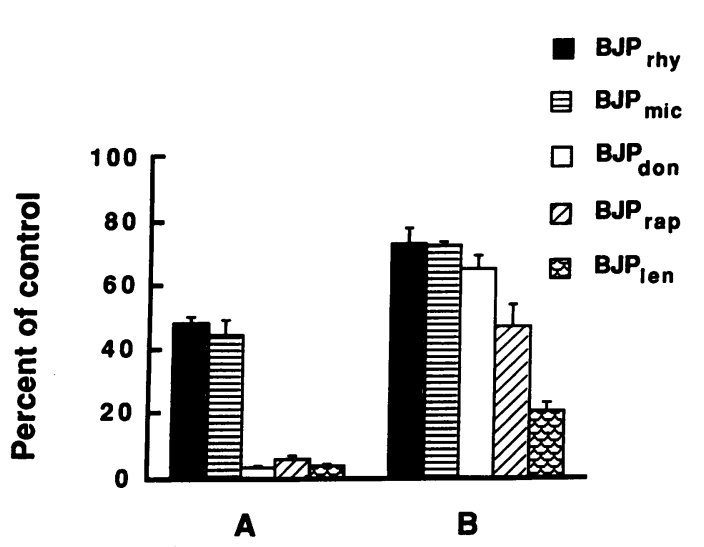

Figure 5. Effect of $\beta$-mercaptoethanol on binding between THP and BJPs ( $n=3$ experiments). In the control groups, THP was added to the wells without $\beta$-mercaptoethanol and incubated for $30 \mathrm{~min}$. $(A)$ THP, $150 \mu \mathrm{g} / \mathrm{ml}$, was added simultaneously with $\beta$-mercaptoethanol, $250 \mathrm{mM}$, to wells coated with BJPs, $2 \mu / \mathrm{ml}$ in PBS, and incubated for $30 \mathrm{~min}$. A marked decrease in binding occurred. $(B)$ THP, 150 $\mu \mathrm{g} / \mathrm{ml}$, was added to wells coated with BJP, $2 \mu \mathrm{g} / \mathrm{ml}$. After $30 \mathrm{~min}$, the wells were washed, then $\beta$-mercaptoethanol, $250 \mathrm{mM}$, was added for $10 \mathrm{~min}$ before the plate was washed and developed the plate. $\beta$ Mercaptoethanol dissociated the THP-BJP complexes. 


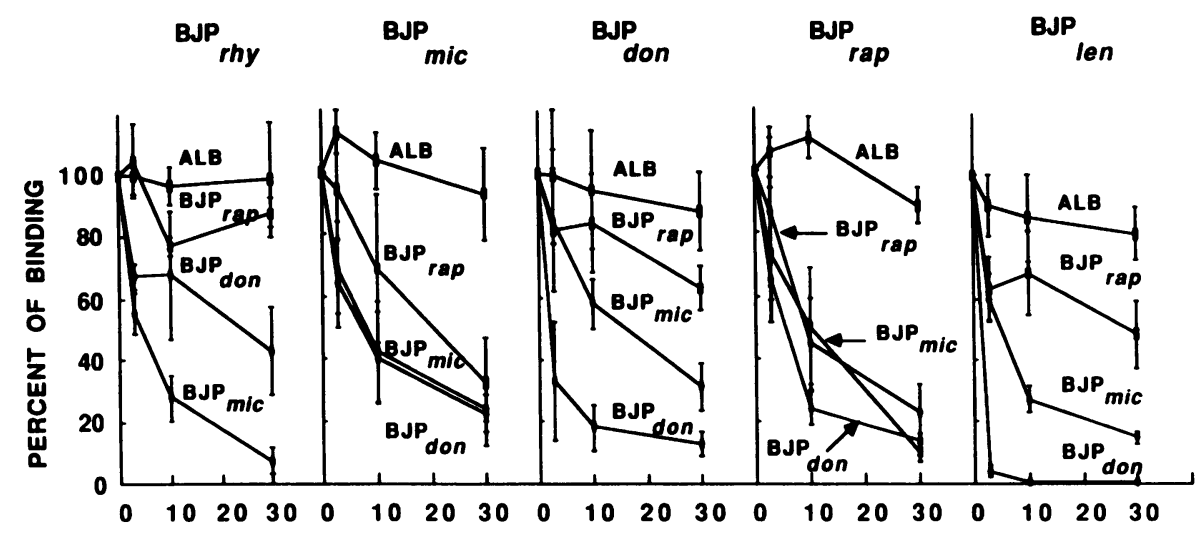

CONCENTRATION OF COMPETITOR PROTEIN, $\mathrm{mg} / \mathrm{ml}$
Figure 6. Results of competition study using $\mathrm{BJP}_{\text {mic }}$ ( $\kappa$ light chain), $\mathrm{BJP}_{\text {rap }}(\kappa$ light chain), and $\mathrm{BJP}_{\text {don }}$ ( $\lambda$ light chain) $(n=3$ experiments). The BJP used to coat the wells is shown at the top of each graph. All three BJPs competed among each other and with the other two BJPs for binding to THP. BJP ${ }_{\text {mic }}$ and $\mathrm{BJP}_{\text {don }}$ possessed the highest affinities for THP and were the strongest competitors. favor coaggregation and subsequent precipitation of the THPBJP complex.

BJPs represent a family of low molecular weight proteins that are structurally homogeneous, but unique, immunoglobulin light chains (27). As suggested originally by Osserman (28), nephrotoxic potential of BJPs appears to relate to certain physicochemical characteristics of these proteins. However, discerning which property(ies) is important has proved difficult. In the current study, all tested BJPs bound THP, but with differing affinities, which presumably was related to distinct physicochemical properties of the BJPs. In the competition study with BJPs, different BJPs replaced each other despite having different isotypes ( $\kappa$ or $\lambda$ ). Other investigators showed that both $\kappa$ and $\lambda$ BJPs deposited as casts in mouse and rat kidneys (13-19, 29). The difference in the binding affinity in the current study was also not related directly to the isoelectric point of BJPs ( Table III). For example, two BJPs (BJP len and BJP $_{r h y}$ ) that had a similar range of isoelectric points had totally different affinities to THP. In general, however, isoelectric point has been found to be an important determinant of coaggregation because proteins with isoelectric points $<5.1$ did not aggregate with THP (15), and cationic BJPs were more nephrotoxic than those BJPs that had lower isoelectric points (13). These data were further supported in a clinical study, which found that those patients that excreted BJPs with isoelectric points $>6.0$ had more severe and irreversible renal failure than those patients that excreted more anionic proteins (30). The different affinities to THP may relate to amino acid substitutions in the hypervariable peptide segment, which differentiates those molecules that have highly conserved three-dimensional structures ( 31 ). This study did not determine that property or peptide sequence responsible for nephrotoxicity, but has provided a means to study further protein nephrotoxicity; defining these nephrotoxic properties is a future direction of this laboratory.

The primary cause of cast formation in myeloma kidney is filtered BJP from the blood stream (12-19). In a previous study, we showed that $\mathrm{BJP}_{\text {mic }}, \mathrm{BJP}_{\text {rap }}$, and $\mathrm{BJP}_{\text {don }}$ aggregated with THP in vitro. $\mathrm{BJP}_{\text {mic }}$ was most potent in causing aggregation, while $\mathrm{BJP}_{\text {rap }}$ was the weakest (15). These data were consistent with the binding affinities of these three BJPs to THP in the current study (Figs. 1 and 2). Thus, binding affinity was closely related to heterotypic aggregation. Because the binding affinity of BJP to THP correlated with aggregation, this characteristic of BJP appeared to be a basic criterion for cast formation. While binding of BJP to THP may be considered a risk factor promoting cast nephropathy in patients with multiple myeloma and Bence Jones proteinuria, more studies are re-

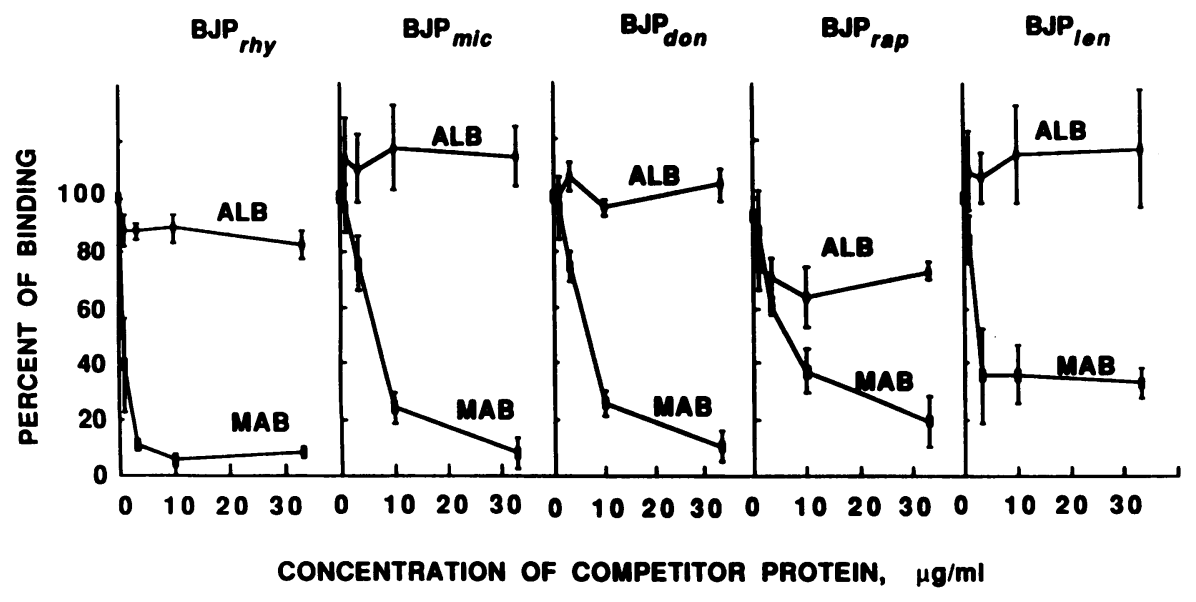

Figure 7. Results of competition study using a mouse monoclonal anti-human THP antibody $(\mathrm{mAb})(n=3$ experiments $)$. All five BJPs were used in this study. To wells coated with the test BJP, $2 \mu \mathrm{g} / \mathrm{ml}$ in PBS, THP, $18.75 \mu \mathrm{g} / \mathrm{ml}$, was added simultaneously with either BSA or mAb, 0.1-33 $\mu \mathrm{g} / \mathrm{ml}$. Because of the low affinity of $\mathrm{BJP}_{\text {rap }}$ and $\mathrm{BJP}_{\text {len }}$ for THP, THP, $150 \mu \mathrm{g} / \mathrm{ml}$, was added simultaneously with antibody to wells coated with these two BJPs. This monoclonal antibody blocked binding of THP to every BJP in a dose-dependent manner. 


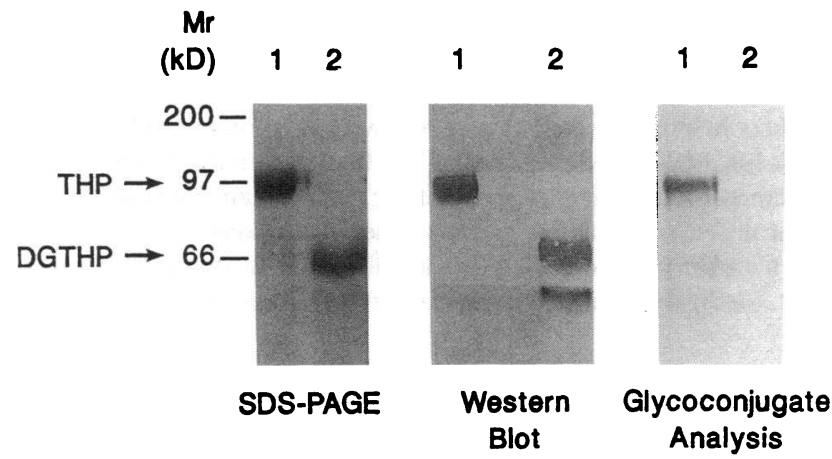

Figure 8. Analysis of THP and deglycosylated THP (DGTHP). SDSPAGE of THP (lane 1) and deglycosylated THP (lane 2) after staining of the gel with Coomassie blue demonstrated the molecular weight of deglycosylated THP decreased to $\sim 66$. The middle panel was a Western blot of THP (lane 1 ) and deglycosylated THP (lane 2), using our monoclonal antibody against human THP. This antibody recognized both native THP and deglycosylated THP and thus reacted to a peptide segment of THP. A smaller band was consistently observed below the deglycosylated THP on the Western blot, but the amount of this protein that was present was too low to be seen using Coomassie blue (first panel, lane 2). The second band of lower molecular weight identified by the monoclonal antibody was probably due to partial proteolysis of THP occurring during the enzymatic deglycosylation process. Glycoconjugate analysis was accomplished using a glycan detection kit. Carbohydrate was not detected on deglycosylated THP (DGTHP) (third panel, lane 2).

quired before the kinetics of binding determined by ELISA may be used as a clinical tool. Cast formation is also related to other factors, such as $\mathrm{pH}$ and ion concentrations in the distal tubular fluid, extracellular fluid volume, use of loop diuretics, hypercalcemia, and concentrations of BJP and THP in the thick ascending limb of the loop of Henle $(2,14-16,29,32-$ 34). For example, $\mathbf{B J P}_{\text {len }}$ was obtained from a patient who had no clinical evidence of cast nephropathy. This BJP did show low binding affinity to THP in our present study. In our tubu-

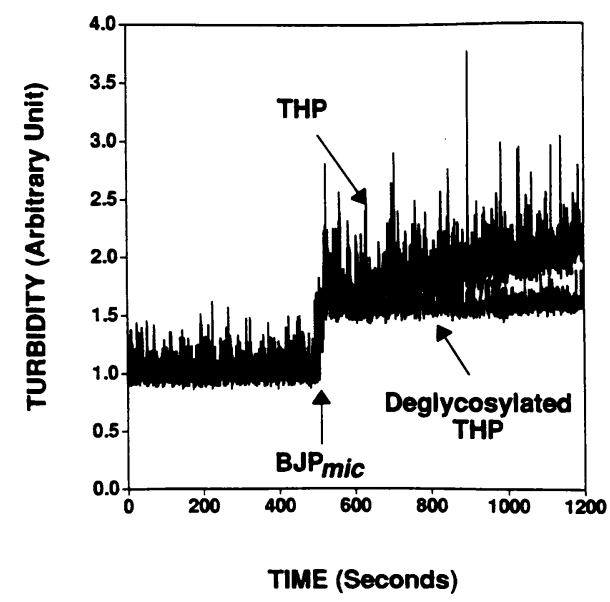

Figure 9. Change in turbidity of solutions containing THP and deglycosylated THP after addition of BJPs ( $n=3$ experiments). Turbidity increased when BJP $_{\text {mic }}$ was added to the solution containing THP. No apparent incremental increase in turbidity was seen when $\mathrm{BJP}_{\text {mic }}$ was added to the solution containing deglycosylated THP.
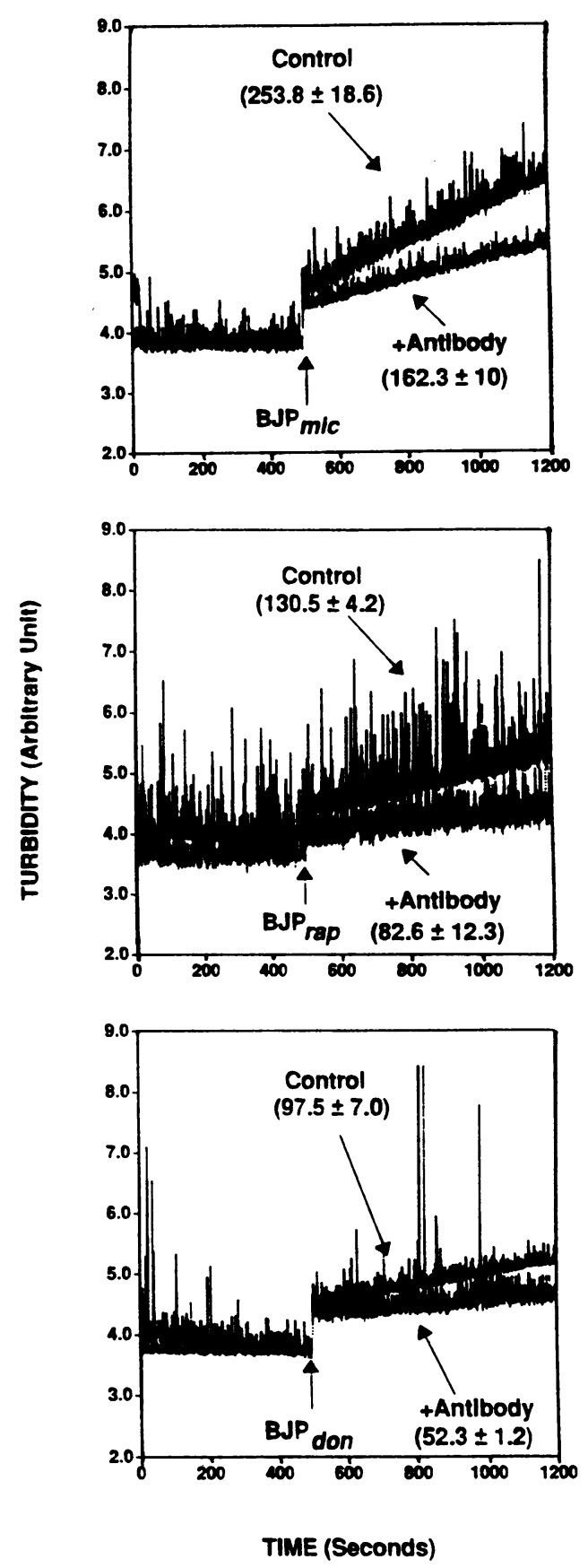

Figure 10. Change in turbidity of solutions containing THP and $\mathrm{BJP}_{\text {mic }}, \mathrm{BJP}_{\text {rap }}$, and $\mathrm{BJP}_{\text {don }}$ in the presence or absence of our monoclonal antibody against human THP. Initial slopes of the aggregation curves were calculated to represent the abilities of BJPs to aggregate THP and were illustrated in parentheses. All three BJPs coaggregated with THP. This effect was partially blocked when the THP solution was preincubated with monoclonal antibody.

lar microperfusion study, $\mathrm{BJP}_{\text {len }}$ did not obstruct the distal nephron of euvolemic rats. However, obstruction from cast formation in the distal nephron occurred when mild extracellular fluid depletion was created (16). In contrast, euvolemia slowed, but did not prevent, intranephronal obstruction from 


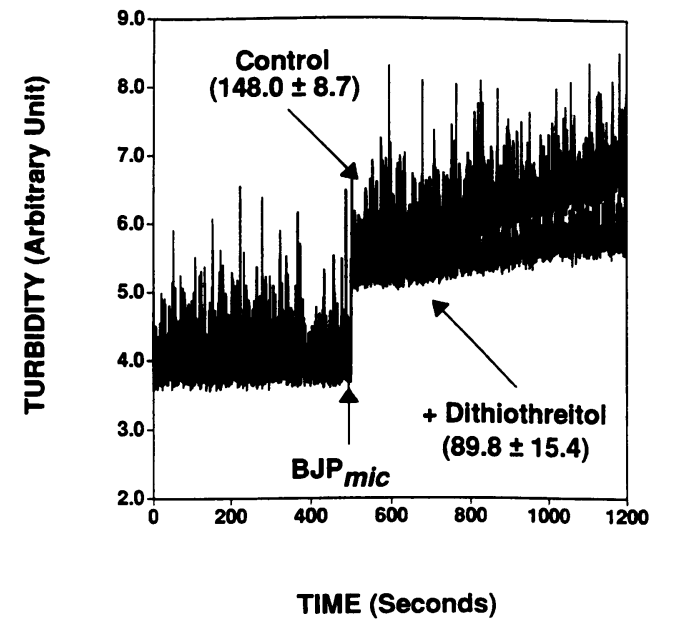

Figure 11. Turbidity measurements of solutions containing THP and BJP $_{\text {mic }}$ in the presence or absence of dithiothreitol, $1.5 \mathrm{mM}$. Aggregation of THP induced by BJP $_{\text {mic }}$ was partially inhibited when dithiothreitol was added simultaneously with $\mathrm{BJP}_{\text {mic }}$.

$\mathrm{BJP}_{\text {don }}$, which had a higher binding affinity for THP. Thus, other factors were also important in modulating BJP-THP aggregation to produce intraluminal obstruction from cast formation. In the management of multiple myeloma, a combined consideration of all these factors should be applied to prevent renal failure.

In summary, we identified a binding site for BJP on the peptide portion of THP. Taken together with previous studies $(15,16)$, in the proper setting binding to THP resulted in coaggregation that ultimately produced distal nephron casts that obstructed the tubule lumen. Previously, we demonstrated that colchicine modified this binding interaction to prevent cast formation in rats (16). In the present study, reducing agents, by breaking the abundant intramolecular disulfide bonds and thus changing the tertiary conformation of THP, decreased binding and subsequent coaggregation of this protein with BJPs. Cysteamine and $N$-acetyl-cysteine have been used clinically to treat other disorders with minor side effects (35). The possible role of reducing agents, with or without colchicine, to prevent cast nephropathy and potentially dissolve casts once they have formed in myeloma patients requires further studies.

\section{Acknowledgments}

The authors thank Dr. J. Claude Bennett and Dr. David G. Warnock for their helpful suggestions and review of this manuscript. We also thank Ms. Melinda McMorris and Mr. Brett Thorn for their technical assistance and the Media Service of the Birmingham Veterans Affairs Medical Center for the photography and illustrations.

This work was supported by the Office of Research and Development, Medical Research Service, Department of Veterans Affairs.

\section{References}

1. Kyle, R. A. 1975. Multiple myeloma: review of 869 cases. Mayo Clin. Proc. 50:29-40.

2. Bernstein, S. P., and H. D. Humes. 1982. Reversible renal insufficiency in multiple myeloma. Arch. Intern. Med. 142:2083-2086.

3. Ganeval, D., C. Rabian, V. Guérin, N. Pertuiset, P. Landais, and P. Jungers. 1992. Treatment of multiple myeloma with renal involvement. $A d v$. Nephrol. 21:347-370.

4. Sanders, P. W., G. A. Herrera, K. A. Kirk, C. W. Old, and J. H. Galla. 1991 Spectrum of glomerular and tubulointerstitial renal lesions associated with monotypical immunoglobulin light chain deposition. Lab. Invest. 64:527-537.

5. Pirani, C. L., F. Silva, V. D'Agati, P. Chander, and L. M. M. Striker. 1987. Renal lesions in plasma cell dyscrasias: ultrastructural observations. Am. J. Kidney Dis. 10:208-221.

6. Iványi, B. 1990. Frequency of light chain deposition nephropathy relative to renal amyloidosis and Bence Jones cast nephropathy in a necropsy study of patients with myeloma. Arch. Pathol. Lab. Med. 114:986-987.

7. Oliver, J. 1945. New directions in renal morphology: a method, its results and its future. Harvey Lect. 40:102-155.

8. Cohen, A. H., and W. A. Border. 1980. Myeloma kidney. An immunomorphogenetic study of renal biopsies. Lab. Invest. 42:248-256.

9. Hoyer, J. R., and M. W. Seiler. 1979. Pathophysiology of Tamm-Horsfall protein. Kidney Int. 16:279-289.

10. Kumar, S., and A. Muchmore. 1990. Tamm-Horsfall protein-uromodulin (1950-1990). Kidney Int. 37:1395-1401.

11. McQueen, E. G. 1962. The nature of urinary casts. J. Clin. Pathol. (Lond.) 15:367-373.

12. Koss, M. N., C. L. Pirani, and E. F. Osserman. 1976. Experimental Bence Jones cast nephropathy. Lab. Invest. 34:579-591.

13. Clyne, D. H., A. J. Pesce, and R. E. Thompson. 1979. Nephrotoxicity of Bence Jones proteins in the rat: importance of protein isoelectric point. Kidney Int. 16:345-352.

14. Sanders, P. W., G. A. Herrera, A. Chen, B. B. Booker, and J. H. Galla. 1988. Differential nephrotoxicity of low molecular weight proteins including Bence Jones proteins in the perfused rat nephron in vivo. J. Clin. Invest. 82:2086-2096.

15. Sanders, P. W., B. B. Booker, J. B. Bishop, and H. C. Cheung. 1990. Mechanisms of intranephronal proteinaceous cast formation by low molecular weight proteins. J. Clin. Invest. 85:570-576.

16. Sanders, P. W., and B. B. Booker. 1992. Pathobiology of cast nephropathy from human Bence Jones proteins. J. Clin. Invest. 89:630-639.

17. Smolens, P., J. L. Barnes, and J. H. Stein. 1986. Effect of chronic administration of different Bence Jones proteins on rat kidney. Kidney Int. 30:874-882.

Table III. Characteristics of BJPs Used in These Studies

\begin{tabular}{|c|c|c|c|c|}
\hline Protein & Isotype & $\begin{array}{l}\text { Isoelectric point } \\
\text { (range) }\end{array}$ & Nephrotoxic & Avidity for THP \\
\hline $\mathrm{BJP}_{r h y}$ & $\kappa$ & $5.2,5.3,5.4 *(5.2-6.6)$ & Yes-documented cast nephropathy & Highest \\
\hline $\mathrm{BJP}_{\text {mic }}$ & $\kappa$ & $7.6-7.7$ & Yes-unknown morphology & High \\
\hline $\mathrm{BJP}_{\text {don }}$ & $\lambda$ & $5.6-5.7$ & Yes-distal nephron cast formation in rats (16) & High \\
\hline $\mathbf{B J P}_{\text {rap }}$ & $\kappa$ & $6.9-7.2$ & Yes-distal nephron cast formation in rats (15) & Low \\
\hline $\mathrm{BJP}_{\text {len }}$ & $\kappa$ & $5.4 *(5.2-6.5)$ & $\mathrm{No}^{\ddagger}$ & Lowest \\
\hline Albumin & - & 4.8 & No & Absent $^{\S}$ \\
\hline
\end{tabular}

* Predominant isoelectric point of the BJP. ${ }^{\ddagger}$ While not nephrotoxic in the human subject and euvolemic rats, this protein did cause cast formation and distal nephron obstruction in hydropenic rats $(16) .{ }^{\S}$ Demonstrated in this and previous $(15,16)$ studies. 
18. Weiss, J. H., R. H. Williams, J. H. Galla, J. L. Gottschall, E. D. Rees, D. Bhathena, and R. G. Luke. 1981. Pathophysiology of acute Bence-Jones protein nephrotoxicity in the rat. Kidney Int. 20:198-210.

19. Solomon, A., D. T. Weiss, and A. A. Kattine. 1991. Nephrotoxic potential of Bence Jones proteins. N. Engl. J. Med. 324:1845-1851.

20. Sanders, P. W., G. A. Herrera, and J. H. Galla. 1987. Human Bence Jones protein toxicity in rat proximal tubule epithelium in vivo. Kidney Int. 32:851861.

21. Bayer, E. A., and M. Wilchek. 1980 . The use of the avidin-biotin complex as a tool in molecular biology. Methods Biochem. Anal. 26:1-45.

22. Pennica, D., W. J. Kohr, W.-J. Kuang, D. Glaister, B. B. Aggarwal, E. Y. Chen, and D. V. Goeddel. 1987. Identification of human uromodulin as the Tamm-Horsfall urinary glycoprotein. Science (Wash. DC). 236:83-88.

23. Ruoslahti, E., and M. D. Pierschbacher. 1987. New perspectives in cell adhesion: RGD and integrins. Science (Wash. DC). 238:491-497.

24. Fletcher, A. P., A. Neuberger, and W. A. Ratcliffe. 1970. Tamm-Horsfall urinary glycoprotein. Biochem. J. 120:417-424.

25. Robinson, J. P., and D. Puett. 1973. Morphological and conformational studies of Tamm-Horsfall urinary glycoprotein. Arch. Biochem. Biophys. 159:615-621.

26. Muchmore, A. V., and J. M. Decker. 1987. Evidence that recombinant IL $1 \alpha$ exhibits lectin-like specificity and binds to homogeneous uromodulin via $N$-linked oligosaccharides. J. Immunol. 138:2541-2546.
27. Solomon, A. 1986. Light chains of immunoglobulins: structural-genetic correlates. Blood. 68:603-610.

28. Osserman, E. F. 1959. Plasma-cell myeloma. N. Engl. J. Med. 261:10061014.

29. Holland, M. D., J. H. Galla, P. W. Sanders, and R. G. Luke. 1985. Effect of urinary $\mathrm{pH}$ and diatrizoate on Bence Jones protein nephrotoxicity in the rat. Kidney Int. 27:46-50.

30. Melcion, C., B. Mougenot, B. Baudouin, P. Ronco, L. Moulonguet-Doleris, P. Vanhille, M. Beaufils, L. Morel-Maroger, P. Verroust, and G. Richet. 1984. Renal failure in myeloma: relationship with isoelectric point of immunoglobulin light chains. Clin. Nephrol. 22:138-143.

31. Stevens, F. J., A. Solomon, and M. Schiffer. 1991. Bence Jones proteins: a powerful tool for the fundamental study of protein chemistry and pathophysiology. Biochemistry. 30:6803-6805.

32. McQueen, E. G., and G. B. Engel. 1966. Factors determining the aggregation of urinary mucoprotein. J. Clin. Pathol. (Lond.). 19:392-396.

33. Alexanian, R., B. Barlogie, and D. Dixon. 1990. Renal failure in multiple myeloma. Pathogenesis and prognostic implications. Arch. Intern. Med. 150:1693-1695.

34. DeFronzo, R. A., R. L. Humphrey, J. R. Wright, and C. R. Cooke. 1975 Acute renal failure in multiple myeloma. Medicine (Baltimore). 54:209-223.

35. Gahl, W. A., R. E. Gregg, J. M. Hoeg, and E. Fisher. 1985. In vivo alteration of a mutant human protein using the free thiol cysteamine. Am. J. Med. Genet. 20:409-417. 